\section{OPEN ACCESS}

Edited by:

Santiago Lozano Calderon, Massachusetts General Hospital and Harvard Medical School,

United States

Reviewed by:

Timothy Hasenoehrl,

Medical University of Vienna, Austria

*Correspondence:

Jennifer Olsen

j.olsen@newcastle.ac.uk

Shruti Turner

s.turner17@imperial.ac.uk

tThese authors have contributed equally to this work and share first authorship

Specialty section:

This article was submitted to Rehabilitation for Musculoskeletal Conditions,

a section of the journal

Frontiers in Rehabilitation Sciences

Received: 12 January 2022 Accepted: 11 February 2022

Published: 07 March 2022

Citation:

Olsen J, Turner S, Chadwell A Dickinson A, Ostler C, Armitage L, McGregor AH, Dupan $S$ and Day $S$

(2022) The Impact of Limited Prosthetic Socket Documentation: A

Researcher Perspective.

Front. Rehabilit. Sci. 3:853414

doi: 10.3389/fresc.2022.853414

\title{
The Impact of Limited Prosthetic Socket Documentation: A Researcher Perspective
}

\begin{abstract}
Jennifer Olsen ${ }^{1 * t}$, Shruti Turner ${ }^{2 * \dagger}$, Alix Chadwell ${ }^{1,3}$, Alex Dickinson ${ }^{4}$, Chantel Ostler ${ }^{5}$, Lucy Armitage ${ }^{6}$, Alison H. McGregor ${ }^{2}$, Sigrid Dupan ${ }^{7}$ and Sarah Day ${ }^{8}$

${ }^{1}$ Intelligent Sensing Laboratory, School of Engineering, Newcastle University, Newcastle upon Tyne, United Kingdom, 2 Sackler MSk Laboratory, Department of Surgery and Cancer, Sir Michael Uren Hub, Imperial College London, London, United Kingdom, ${ }^{3}$ Human Movement and Rehabilitation Research Group, University of Salford, Salford, United Kingdom, ${ }^{4}$ Faculty of Engineering and Physical Science, University of Southampton, Southampton, United Kingdom, ${ }^{5}$ Portsmouth Enablement Centre, Portsmouth Hospital University National Health Service (NHS) Trust, St Marys Hospital, Portsmouth, United Kingdom, ${ }^{6}$ School of Mechanical, Materials, Mechatronic and Biomedical Engineering, University of Wollongong, Wollongong, NSW, Australia, ${ }^{7}$ Edinburgh Neuroprosthetics Laboratory, School of Informatics, University of Edinburgh, Edinburgh, United Kingdom, ${ }^{8}$ Department of Biomedical Engineering, University of Strathclyde, Glasgow, United Kingdom
\end{abstract}

The majority of limb prostheses are socket mounted. For these devices, the socket is essential for adequate prosthetic suspension, comfort, and control. The socket is unique among prosthetic components as it is not usually mass-produced and must instead be custom-made for individual residual limbs by a prosthetist. The knowledge of what constitutes "good" socket fit is gained by expert prosthetists and technicians over years of experience, and rarely documented. The reliance on tacit knowledge makes it difficult to standardize the criteria for a well-fitting socket, leading to difficulties understanding the impact of socket fit. Despite its importance, the workflow for socket fitting is often overlooked in literature. Due to the customized nature of sockets, if information is provided in literature, generally only the type of socket and suspension mechanism is noted, with information regarding the fitting and manufacturing processes omitted. In this article, the concerns, issues and consequences arising from lack of upper and lower limb socket documentation are discussed from a researcher perspective, supported by healthcare professionals and socket fabrication specialists. Key changes are proposed to the way socket manufacturing and evaluation are documented to assist future research.

Keywords: prosthetics, sockets, documentation, socket fit, prosthetic socket

\section{INTRODUCTION}

The majority of limb prostheses are attached to the human body using a prosthetic socket. For these devices, the socket is one of the most critical components (1-3) for suspension, comfort, and control $(1,4-6)$.

The socket is unique among prosthetic components, as it is the only part that is not massproduced, instead it is custom-made for each individual residual limb by a prosthetist or technician (4). The profession of "Prosthetist and Orthotist", also known as "Orthopaedic Technician", is legally protected in several nations (7). For countries without protected profession directives, the establishment of international standards and regulatory bodies for devices and training is of utmost importance (8). Although necessary to preserve patient safety, the regulated nature of the 
profession limits the amount of information that is publicly shared about manufacturing processes. The evidence and description of their workflow is frequently missing from literature, and it is common for research evaluating prosthetic components (e.g., a knee joint) to note the type of socket and suspension mechanism but include no precise information about fit or manufacturing process. Consequently, it is not possible to evaluate to what extent socket fit has impacted the results of studies analyzing other prosthesis-related outcome metrics, such as the dependability of myoelectric control (9).

The socket acts as the interface between the body and prosthesis, facilitating load bearing (1) and proprioception in lower-limb devices. In myoelectric prostheses, the socket houses electrodes which allow the transmission of control signals (10). Despite functional differences between upper and lower limb prostheses, the key factors affecting user acceptance and function are similar (11), with discomfort and diminished prosthesis control being the leading causes of abandonment and dissatisfaction $(11,12)$.

Each socket's shape is derived from the anatomy, requiring complex design modifications based on factors such as location and level of amputation or limb absence, bony prominences and tissue consistency, the quality and load bearing capabilities of the tissues, and scars (13).

Currently, there is neither a quantifiable nor a universally accepted definition of what constitutes a well-fitting socket. Although guidelines exist regarding how to administer specific socket designs and manage pressure distribution $(6,14)$, socket creation relies heavily on the skills and knowledge of individual prosthetists gained from years of experience $(6,15,16)$, and the subjective feedback from prosthesis users, which makes it difficult to standardize the quality of socket fit (15).

The article aims to highlight the issues caused by the lack of published information surrounding prosthetic socket manufacturing and evaluation-the key stages of prosthetic socket provision identified by the authors. The article takes the format of an opinion piece; a first-hand account from a group of seven biomedical engineering researchers and two clinician researchers (one physiotherapist and one prosthetist). It is hoped that formally documenting some of the key issues will raise questions to inform future research and evidence the requirements to obtain a clear definition of a well-fitting socket. Recommendations are proposed to address the issues discussed in the article to enhance the understanding of socket fit in research.

\section{SOCKET DESIGN AND MANUFACTURING}

The traditional process for creating a socket is similar for both upper and lower limbs. Prosthetists mark bony prominences and important areas on the limb and then take a Plaster of Paris cast, capturing their markings and hand sculpting the cast as it dries. The negative cast is used to produce a positive plaster replica of the limb which is then rectified (a manual process where material is added and removed to refine the fit and comfort of the socket) $(14,17)$. The socket, or a temporary diagnostic "check" socket, is then produced and the fit is confirmed by the prosthetist (17-19). However, despite the importance of these checks, many intermediate steps in the socket fitting process are not documented in literature e.g., prosthetists check for pressure and movement within the socket and shaping of the socket trimline, all of which rely heavily on experience (19).

It is plausible that some steps of socket production, such as hand sculpting, cannot be quantified, or even verbalized. The skills required to sculpt and rectify a prosthetic socket go far beyond the initial training given to prosthetists. Achieving a good fit relies directly on tacit knowledge, the prosthetist's experience and the feel of the limb under palpation and manipulation, and its underlying structures.

Digital scanning has become increasingly common as a method of capturing limb geometry, used in conjunction with Computer Aided Design/Manufacturing (CAD/CAM) to create sockets $(20,21)$. Generally, the aim of digitizing socket manufacture is to minimize workshop time, permit repeated production, provide a more autonomous method of production, and allow rapid prototyping. The process also leaves a perpetual digital record of design. However, to ensure the tactile and tacit experience of clinicians is accurately captured by digital platforms, it should be documented. Until this is done, there will remain a barrier to reliably producing sockets using digital methods such as direct limb scanning and CAD/CAM. Complex digital scanning techniques have been trialed in research (22, 23), and attempts have been made to identify common trends in CAD/CAM socket rectification (24), but a method that incorporates the feel of socket fit is yet to emerge.

As current methods are "tried and tested" there is little information to guide what is "safe" for novel methods and materials. Standard ISO10328:2016 (25) exists for structural testing of lower-limb prosthetic components but does not specifically describe testing of the socket itself, and no such standards exist for upper-limb devices. This limits the ability to screen and verify the safety of new socket designs, materials and fabrication methods like additive manufacturing. Safety is the utmost priority for clinicians; therefore, the lack of published safety guidelines will prevent novel methods such as $3 \mathrm{D}$ printing moving from research and private clinics to a mainstream manufacturing method (26).

\subsection{Workflow Omission in Research Reporting}

Prosthetics researchers often rely on the input of a registered prosthetist and in-house prosthetics technicians to manufacture research sockets. The prosthetist/technician's technique is rarely reported in subsequent publications. By omitting their workflow and recording the socket as if it was a prefabricated component, a wealth of knowledge is lost. The decisions that lead to the chosen socket design, including how long the procedure took, the cost, the level of rectification, how many attempts were made to obtain a satisfactory socket fit, and details of each participant's individual limb are rarely, if ever, documented in literature. Omitting the workflow that precedes and covers socket production in research 
studies may limit their external validity, or the application of their findings.

The mechanical performance of prototype socket designs and materials may differ substantially depending upon the size and shape of the limb for which they are designed. Comparisons about novel materials cannot be made if materials and how they are used (e.g., layers, thickness) are not noted. Additionally, the scarcity of modern workflow documentation from clinics makes room for the misrepresentation of capabilities regarding modern manufacturing methods such as $3 \mathrm{D}$ printing and digital scanning. For researchers who work independently from clinicians, this can create the illusion that digital methods are a ready-to-use alternative which does not require clinical intervention. This misconception can be detrimental to clinicians and has the potential to impact patient safety.

\subsection{Materials}

The evolution of materials used to manufacture sockets has been documented for over a century-transitioning from wood, to leather, to modern polymers and carbon fiber $(26,27)$. However, the reasons for choosing a specific material or the number of layers used in laminates are rarely noted. It is not clear what factors were considered when phasing out older materials or bringing in new ones. Issues of cost, expertise, patient demand, or manufacturing materials are likely to be important but are not noted making transitions or improvements problematic and at times may lead researchers to "re-invent the wheel".

\subsection{Evolution of Socket Types}

For lower-limb, there have been advancements in the load distributions of sockets (28-33), and suspension mechanisms $(2,34)$. However, apart from the materials utilized and stand-out novel designs (35), documented upper-limb socket styles and manufacturing techniques have remained relatively unchanged for decades (36). Researchers rely on original design specifications for sockets $(28,29,37,38)$, however, prosthetists will create hybrids and modifications of original designs as they see fit. Such changes have not been documented although are accepted as common knowledge in the field (39).

\section{OUTCOME MEASUREMENT}

To understand the impact of socket design and manufacturing, as well as understand where improvements are needed, it is necessary to evaluate the outcome of the process. This is often undertaken clinically at the individual level by a prosthetist reviewing the fit of the socket and establishing whether the patients finds it comfortable. Currently, socket fit and comfort are assessed using simple scales. However, there is no universally accepted definition for socket comfort or fit. Moreover, there is no single accepted measurement tool for clinicians to assess these outcomes or for users to feedback.

\subsection{Definition of Socket Fit and Comfort}

Often, the terms socket fit and comfort are used interchangeably. Neither term has a universally accepted definition, although it is generally accepted that socket fit refers to diverse metrics assessed by a prosthetist regarding the volume and shape match to the limb, safety and suspension, whereas socket comfort is a subjective measure reported by the prosthesis user.

There are no defined rules for what constitutes a good socket fit, hence there is sparse literature detailing how to assess whether a socket is well-fitting. Interface stress (the pressure and shear between the socket and residual limb) has been identified as an important factor $(3,11,40)$. Whilst little is defined about good fit, much is known about the context of poor fit. Most literature refers to the medical consequences of ill-fitting sockets or inadequate distribution of load, e.g., skin breakdown and deep tissue injury (41-44). Little is documented about the day-to-day impact on quality-of-life stemming from poor socket fit $(3,45)$.

Socket comfort consistently ranks highly as a factor contributing to prosthesis abandonment $(12,46)$. Socket comfort can be used as a measure of socket fit (47), with correlation between user-reported comfort scores and prosthetist evaluation of the socket fit. However, first-hand experience working with people with lower-limb amputations who self-report high levels of comfort and satisfaction, suggests that this is not always the case, but no documented examples have been found.

\subsection{Socket Satisfaction Measurement}

Subjective metrics such as comfort are important in the socket fitting process, since user approval is crucial for prosthesis acceptance. Without user acceptance of the socket, a prosthesis is likely to be abandoned regardless of other metrics. Attempts have been made to quantify socket comfort in the form of standardized scales in evaluation questionnaires. To date, the Socket Comfort Score (SCS), and Comprehensive Lower-Limb Amputee Socket Survey (CLASS) are the only scales which specifically address socket comfort $(47,48)$. The SCS and CLASS do not report the cause of discomfort, simply the presence and magnitude, and are validated for use with lower-limb prosthesis users only. Metrics such as the Trinity Amputation and Prosthesis Experience Scales (TAPES) (49) and Prosthesis Evaluation Questionnaire (PEQ) (50) have high validity and ask specific questions about socket fit. However, they do not provide an in-depth assessment of socket comfort, instead focusing on overall wellbeing and general satisfaction with the prosthesis. There is a lack of consensus around what aspects should be measured and how (51), evidenced by the different focus of existing tools.

Currently, a disconnect exists between the methods used in research and those used in clinical practice to evaluate socket satisfaction at the point of provision. Research focus tends to revolve around assessing and correcting interface pressures with novel technology, based on objective outcome measures (5254). However, in clinics, assessment of interface pressures is generally done without specialist equipment; instead, subjective measures such as monitoring the redness of a residual limb after doffing the prosthesis are commonly used in combination with patient feedback (35). Measurement scales may be used to evaluate socket comfort; however, this can be misleading due to varying personal experiences with pain (55), as well as individuals who have reduced sensation in their residual limb (56). For this reason, the changes in scores are often considered more pertinent to consider than the absolute scores reported. 
Communication between patients and their clinicians is important in the evaluation of socket comfort. The importance of language to communicate subjective experiences has been illustrated by Bourke in the context of pain (55). The words chosen by patients to communicate the same experience may differ to each other. For example, to one person a given level of pressure may be discomfort, whereas to another it may be pain. The interpretation of the clinician is also a factor in understanding the experiences of the patient.

There are currently no scales in existence which allow qualitative measures, such as user explanations for their responses or clinician notes to be taken into context, which has led some researchers to develop bespoke surveys to document socket fit, comfort and its primary impacts $(3,17)$. In recent years, research groups have called for the introduction of improved quantifiable outcome measures of patient socket satisfaction (57, 58). In terms of gauging socket satisfaction, none of the existing scales are internationally recognized as the "standard" metric, hence it is difficult to draw comparisons between the outcomes of various novel prosthetic interventions. Documentation of the usage of SCS and similar scales within clinics has not yet been reported, making it difficult to assess whether any existing scales should be adopted as a universal metric. Moreover, there are no scales designed specifically to assess comfort for upperlimb sockets.

\subsection{Outcome Sharing}

The current evaluation measures for socket satisfaction only gauge how the wearer is feeling at the time of the assessment, but do not give a detailed picture of the changes that may occur as the person uses their limb in their daily activities. Without data on how socket satisfaction changes over time and the impacts this has on the wearer's day-to-day activities, a wealth of knowledge and the potential for learning from past interventions is lost. In addition to this, the reasons for which sockets are revised (e.g., limb volume changes, mechanical failure, discomfort) are not widely documented.

In order to assess novel socket designs, a comparison of their performance against a similar, existing socket is required. Current comparisons rely on case-studies, as large amounts of data relating to the performance of specific socket types is not accessible. Atypical and complex socket fitting cases are common, and certain levels of amputation are much less prevalent, e.g., upper-limb amputation (26, 59-61). Therefore, it would be beneficial to have global pooled data sharing between clinics and researchers to facilitate a greater understanding of sockets prescribed and trialed for different circumstances. However, for the sharing of clinical outcomes to be possible, it is necessary to have a standardized protocol for what information should be collected and how, and which outcome measurement tool should be used.

\section{PROPOSED RECOMMENDATIONS}

The issues raised in this article are key inhibitors for the development of new socket technology, and the interpretation of wider prosthetics research. The common theme is how sockets are documented, irrespective of the stage at which they occur in the limb provision process.

At the socket design and manufacturing stage, up-to-date technical specifications of socket designs, alongside an overview of modern manufacturing and decision-making processes should be made accessible. To enable this, a set of standardized reporting guidelines for evaluating novel prosthetic elements should be produced. In addition, the establishment of an ISO standard for structural testing of sockets and upper-limb prostheses equivalent to that of ISO 10328:2016 would also be useful.

To allow clear communication in prosthetics research and practice, a greater understanding of socket fit and socket comfort, from clinician and user perspectives, is needed in order to establish agreed definitions. This would enable a standardized clinical assessment of both socket fit and comfort. The scales should be validated for both upper and lower limb sockets, accounting for their different functional requirements.

Reporting guidelines should be created to facilitate global data sharing of socket fitting case studies, alongside the reported success of each fitting. For this to be possible, a standardized approach for outcome assessment should be established, including whether the socket provision was successful (and what success means), reported feedback from the user and what special measures were taken to enhance the fit. Sharing of clinical outcome assessments would be beneficial to research articles exploring the outcome of prosthetic socket manufacture, design, and fitting, but also the evaluation of other prosthetic components. This sharing of information could influence best practice and lead to improvements in both clinical practice and research. A standardized protocol would allow research to be comparable and heighten the value of evidence.

\section{CONCLUSIONS}

This article proposes there should be detailed published information regarding the elements of socket design and fabrication that are currently based upon implicit knowledge. It provides a call for a clear, universal definition of what constitutes a good socket fit and how it differs from comfort, based on an in depth understanding of clinician and user experience. Finally, it highlights the need for universally accepted outcome measures to evaluate the fit of a prosthetic socket and enhanced data sharing between clinics and researchers.

\section{DATA AVAILABILITY STATEMENT}

The original contributions presented in the study are included in the article/supplementary material, further inquiries can be directed to the corresponding author/s.

\section{AUTHOR CONTRIBUTIONS}

JO and ST: conceptualization and writing-original draft preparation and editing. $\mathrm{AC}, \mathrm{AD}, \mathrm{CO}, \mathrm{LA}, \mathrm{AM}, \mathrm{SDu}$, and SDa: writing-review and editing. All authors have read and agreed to the published version of the manuscript. 


\section{FUNDING}

This work was supported by the Engineering and Physical Sciences Research Council (EPSRC), U.K., under

\section{REFERENCES}

1. Lake C, Supan TJ. The incidence of dermatological problems in the silicone suspension sleeve user. J Prosthet Orthot. (1997) 9:97-106. doi: 10.1097/00008526-199700930-00003

2. Stevens PM, Depalma RR, Wurdeman SR. Transtibial socket design, interface, and suspension: a clinical practice guideline. J Prosthet Orthot. (2019) 31:1728. doi: 10.1097/JPO.0000000000000219

3. Turner S, McGregor AH. Perceived effect of socket fit on major lower limb prosthetic rehabilitation: a clinician and amputee perspective. Arch Rehabil Res Clin Transl. (2020) 2:100059. doi: 10.1016/j.arrct.2020.100059

4. Wernke MM, Schroeder RM, Haynes ML, Nolt LL, Albury AW, Colvin JM. Progress toward optimizing prosthetic socket fit and suspension using elevated vacuum to promote residual limb health. Adv Wound Care. (2017) 6:233-9. doi: 10.1089/wound.2016.0719

5. Pezzin LE, Dillingham TR, MacKenzie EJ, Ephraim P, Rossbach P. Use and satisfaction with prosthetic limb devices and related services. Arch Phys Med Rehabil. (2004) 85:723-9. doi: 10.1016/j.apmr.2003.06.002

6. Schofield JS, Schoepp KR, Williams HE, Carey JP, Marasco PD, Hebert JS. Characterization of interfacial socket pressure in transhumeral prostheses: a case series. PLoS ONE. (2017) 12:e0178517. doi: 10.1371/journal.pone.0178517

7. European Commission. Regulated Professions Database. (2021). Available online at: https://ec.europa.eu/growth/tools-databases/regprof/index.cfm? action $=$ profession\&id_profession $=1120 \& \operatorname{tab}=$ countries $\&$ quid $=2 \& \operatorname{mode}=$ asc\&maxRows $={ }^{*}$ \#top (accessed October 14, 2021).

8. Clarke L, Puli L, Ridgewell E, Dillon MP, Anderson S. Regulation of the global orthotist/prosthetist workforce, and what we might learn from allied health professions with international-level regulatory support: a narrative review. Hum Resour Health. (2021) 19:83. doi: 10.1186/s12960-021-00625-9

9. Chadwell A, Kenney L, Thies S, Galpin A, Head J. The reality of myoelectric prostheses: understanding what makes these devices difficult for some users to control. Front Neurorobot. (2016) 10:7. doi: 10.3389/fnbot.2016.00007

10. Head JS, Howard D, Hutchins SW, Kenney L, Heath GH, Aksenov AY. The use of an adjustable electrode housing unit to compare electrode alignment and contact variation with myoelectric prosthesis functionality: a pilot study. Prosthet Orthot Int. (2016) 40:123-8. doi: 10.1177/0309364614545417

11. Paternó L, Ibrahimi M, Gruppioni E, Menciassi A, Ricotti L. Sockets for limb prostheses: a review of existing technologies and open challenges. IEEE Trans Biomed Eng. (2018) 65:1996-2010. doi: 10.1109/TBME.2017.2775100

12. Biddiss E, Chau T. Upper-limb prosthetics: critical factors in device abandonment. Am J Phys Med Rehabil. (2007) 86:977-87. doi: 10.1097/PHM.0b013e3181587f6c

13. Rommers G, Vos L, Klein L, Groothoff J, Eisma W. A study of technical changes to lower limb prostheses after initial fitting. Prosthet Orthot Int. (2000) 24:28-38. doi: 10.1080/03093640008726519

14. DeLisa JA, Gans BM, Walsh NE. Physical Medicine and Rehabilitation: Principles and Practice. Philadelphia, PA: Lippincott Williams and Wilkins (2005).

15. Safari MR, Rowe P, McFadyen A, Buis A. Hands-off and Handson casting consistency of amputee below knee sockets using magnetic resonance imaging. Sci World J. (2013) 2013:486146. doi: 10.1155/2013/ 486146

16. Trower TA. Changes in lower extremity prosthetic practice. Phys Med Rehabil Clin N Am. (2006) 17:23-30. doi: 10.1016/j.pmr.2005.10.003

17. Olsen J, Day S, Dupan S, Nazarpour K, Dyson M. 3D-printing and upper-limb prosthetic sockets: promises and pitfalls. IEEE Trans Neural Syst Rehabil Eng. (2021) 29:3057984. doi: 10.1109/TNSRE.2021.3057984

18. Hsu LH, Huang G, Lu C, Hong D, Liu S. The development of a rapid prototyping prosthetic socket coated with a resin layer studentship number 2281137 from $\mathrm{EP} / \mathrm{N} 509528 / 1$ and $\mathrm{EP} / \mathrm{R} 51309 \mathrm{X} / 1 \quad \mathrm{JO}), \mathrm{EP} / \mathrm{R} 014213 / 1 \quad \mathrm{AD}$ and $\mathrm{CO})$, and Scar Free Foundation, no grant number given (ST and $\mathrm{AM})$.

for transtibial amputees. Prosthet Orthot Int. (2010) 34:37-45. doi: $10.3109 / 03093640902911820$

19. Herbert N, Simpson D, Spence WD, Ion W. A preliminary investigation into the development of 3-D printing of prosthetic sockets. J Rehabil Res Dev. (2005) 42:141-6. doi: 10.1682/JRRD.2004.08.0134

20. Steer JW, Stocks O, Parsons J, Worsley PR, Dickinson AS. Ampscan: a lightweight python package for shape analysis of prosthetics and orthotics. J Open Source Softw. (2020). 5:2060. doi: 10.21105/joss.02060

21. NiaTech. Nia Technology. (2021). Available online at: https://niatech.org/ technology/ (accessed April 30, 2021).

22. Petron A, Duval JF, Herr H. Tools for Measuring Limb Tissue BiomechanicsBiomechatronics. (2021). Available online at: https://biomech.media.mit.edu/ portfolio_page/socket-fit/ (accessed: March 09, 2021).

23. Sengeh DM, Herr H. A variable-impedance prosthetic socket for a transtibial amputee designed from magnetic resonance imaging data.J Prosthet Orthot. (2013) 25:129-37. doi: 10.1097/JPO.0b013e31829be19c

24. Dickinson A, Diment L, Morris R, Pearson E, Hannett D, Steer J. Characterising residual limb morphology and prosthetic socket design based on expert clinician practice. Prosthesis. (2021) 3:280-99. doi: $10.3390 /$ prosthesis 3040027

25. International Organization for Standardization. ISO 10328:2016 (2016) Available online at: https://www.iso.org/standard/70205.html?browse=tc

26. Lake C. The evolution of upper limb prosthetic socket design. J Prosthet Orthot. (2008) 20:85-92. doi: 10.1097/JPO.0b013e31817d2f08

27. Murphy EF. Sockets, linings and interfaces. Clin Prosthet Orthot. (1984) 8:4-10.

28. Staats TB, Lundt J. The UCLA total surface bearing suction below-knee prosthesis. Clin Prosthet Orthot. (1987) 11:117-23. doi: 10.3109/03093648709078193

29. Radcliffe CW, Foort J. The Patellar-Tendon-Bearing below-Knee Prosthesis, Berkeley, CA: University of California, Biomechanics Laboratory (1961).

30. Hachisuka K, Dozono K, Ogata H, Ohmine S, Shitama H, Shinkoda K. Total surface bearing below-knee prosthesis: advantages, disadvantages, and clinical implications. Arch Phys Med Rehabil. (1998) 79:783-9. doi: 10.1016/S0003-9993(98)90356-2

31. Isaacson BM, Lin SC, Rothberg DL. Improvement in functional outcomes with the infinite socket. J Prosthet Orthot. (2018) 30:181-186. doi: 10.1097/JPO.0000000000000210

32. Revo Labs. Revo Labs: Why Adjustable Sockets. (2021). Available online at: https://revo-labs.com/\#who-we-are (accessed October 15, 2021).

33. Martin Bionics. Above-Knee Socket-Less Socket. (2021). Available online at: https://martinbionics.com/above-knee-socket-less-socket/ (accessed October 15, 2021)

34. Fatone S, Caldwell R. Northwestern University flexible subischial vacuum socket for persons with transfemoral amputation: part 2 description and preliminary evaluation. Prosthet Orthot Int. (2017) 41:246-50. doi: $10.1177 / 0309364616685230$

35. Alley RD, Williams T, Albuquerque MJ, Altobelli DE. Prosthetic sockets stabilized by alternating areas of tissue compression and release. J Rehabil Res Dev. (2011) 48:679-96. doi: 10.1682/JRRD.2009.12.0197

36. Vujaklija I, Farina D. 3D printed upper limb prosthetics. Expert Rev Med Dev. (2018). 15:505-12. doi: 10.1080/17434440.2018.1494568

37. Fishman S, Kay HW. The munster-type below-elbow socket, an evaluation. Artif Limbs. (1964) 8:4-14.

38. Billock JN. The Northwestern University supracondylar suspension technique for below-elbow amputations. Orthot Prosthet. (1972) 26:16-23.

39. Kay HW, Cody KA, Hartmann G, Casella DE. The Munster-type below-elbow socket, a fabrication technique. Artif Limbs. (1965) 9:4-25.

40. Bramley J, Worsley P, Bostan L, Bader D, Dickinson A. Establishing a measurement array to assess tissue tolerance during loading 
representative of prosthetic use. Med Eng Phys. (2020) 78:39-47. doi: 10.1016/j.medengphy.2020.01.011

41. Bouten CV, Oomens CW, Baaijens FP, Bader DL. The etiology of pressure ulcers: skin deep or muscle bound? Arch Phys Med Rehabil. (2003) 84:616-9. doi: 10.1053/apmr.2003.50038

42. Stekelenburg A, Gawlitta D, Bader DL, Oomens CW. Deep tissue injury: how deep is our understanding? Arch Phys Med Rehabil. (2008) 89:1410-3. doi: 10.1016/j.apmr.2008.01.012

43. Levy SW. Skin problems of the leg amputee. Prosthet Orthot Int. (1980) 4:37-44. doi: 10.3109/03093648009103113

44. Graser M, Day S, Buis A. Exploring the role of transtibial prosthetic use in deep tissue injury development: a scoping review. BMC Biomed Eng. (2020) 2:2. doi: 10.1186/s42490-020-0036-6

45. Turner S, Belsi A, McGregor AH. Issues faced by people with amputation (s) during lower limb prosthetic rehabilitation: a thematic analysis. Prosthet Orthot Int. (2021) 46:61-7. doi: 10.1097/PXR.0000000000000070

46. Espinosa M, Nathan-Roberts D. Understanding prosthetic abandonment. Proc Hum Fact Ergon Soc Annu Meet. (2019) 63:1644-8. doi: 10.1177/1071181319631508

47. Hanspal R, Fisher K, Nieveen R. Prosthetic socket fit comfort score. Disabil Rehabil. (2003) 25:1278-80. doi: 10.1080/09638280310001603983

48. Gailey R, Kristal A, Lucarevic J, Harris S, Applegate B, Gaunaurd I. The development and internal consistency of the comprehensive lower limb amputee socket survey in active lower limb amputees. Prosthet Orthot Int. (2019) 43:80-7. doi: 10.1177/0309364618791620

49. Gallagher P, MacLachlan M. The Trinity amputation and prosthesis experience scales and quality of life in people with lower-limb amputation. Arch Phys Med Rehabil. (2004) 85:730-6. doi: 10.1016/j.apmr.2003. 07.009

50. Legro MW, Reiber GD, Smith DG, del Aguila M, Larsen J, Boone D. Prosthesis evaluation questionnaire for persons with lower limb amputations: assessing prosthesis-related quality of life. Arch Phys Med Rehabil. (1998) 79:931-8. doi: 10.1016/S0003-9993(98)90090-9

51. Ostler C, Scott H, Sedki I, Kheng S, Donovan-Hall M, Dickinson A, et al. From outcome measurement to improving health outcomes following lower limb amputation-making outcome measurement work from a clinical practice perspective. [Preprint]. (2020). doi: 10.31224/osf.io/kfgdy

52. Armitage L, Rajan G, Kark L, Simmons A, Prusty BG. Simultaneous measurement of normal and shear stress using fiber Bragg grating sensors in prosthetic applications. IEEE Sens J. (2019) 19:7383-90. doi: 10.1109/JSEN.2019.2914702

53. Hopkins MO. Smart Sockets for Lower Limb Prostheses. London: Imperial College London (2018).
54. Prince M, Kenney LP, Howard D. A pin-array method for capturing tissue deformation under defined pressure distributions and its application to prosthetic socket design. Med Eng Phys. (2020) 84:136-43. doi: 10.1016/j.medengphy.2020.08.003

55. Bourke J. The Story of Pain: From Prayer to Painkillers. Springer (2017). doi: 10.1891/1062-8061.25.1.180

56. Harden RN, Gagnon CM, Khan A, Wallach G, Zereshki A. Hypoesthesia in the distal residual limb of amputees. PMR. (2010) 2:607-11. doi: 10.1016/j.pmrj.2010.03.033

57. Safari MR, Meier MR. Systematic review of effects of current transtibial prosthetic socket designs-Part 1: qualitative outcomes. J Rehabil Res Dev. (2015) 52:491-508. doi: 10.1682/JRRD.2014.08.0183

58. Pirouzi G, Abu Osman NA, Eshraghi A, Ali S, Gholizadeh H, Wan Abas WA. Review of the socket design and interface pressure measurement for transtibial prosthesis. ScientificWorldJournal. (2014) 2014:849073. doi: 10.1155/2014/849073

59. Ziegler-Graham K, MacKenzie EJ, Ephraim PL, Travison TG, Brookmeyer R. Estimating the Prevalence of Limb Loss in the United States: 2005 to 2050. Arch Phys Med Rehabil. (2008) 89:422-9. doi: 10.1016/j.apmr.2007.11.005

60. Jain AS, Robinson DPH, Davies A. Synopsis of Causation; Upper Limb Amputation. Ministry of Defence, editor. (2008).

61. Dillingham TR, Braza DW. Upper limb amputations. In: Essentials of Physical Medicine and Rehabilitation. Elsevier (2008). p. 595-8. doi: 10.1016/B978-1-4160-4007-1.50110-3

Conflict of Interest: The authors declare that the research was conducted in the absence of any commercial or financial relationships that could be construed as a potential conflict of interest.

Publisher's Note: All claims expressed in this article are solely those of the authors and do not necessarily represent those of their affiliated organizations, or those of the publisher, the editors and the reviewers. Any product that may be evaluated in this article, or claim that may be made by its manufacturer, is not guaranteed or endorsed by the publisher.

Copyright (c) 2022 Olsen, Turner, Chadwell, Dickinson, Ostler, Armitage, McGregor, Dupan and Day. This is an open-access article distributed under the terms of the Creative Commons Attribution License (CC BY). The use, distribution or reproduction in other forums is permitted, provided the original author(s) and the copyright owner(s) are credited and that the original publication in this journal is cited, in accordance with accepted academic practice. No use, distribution or reproduction is permitted which does not comply with these terms. 